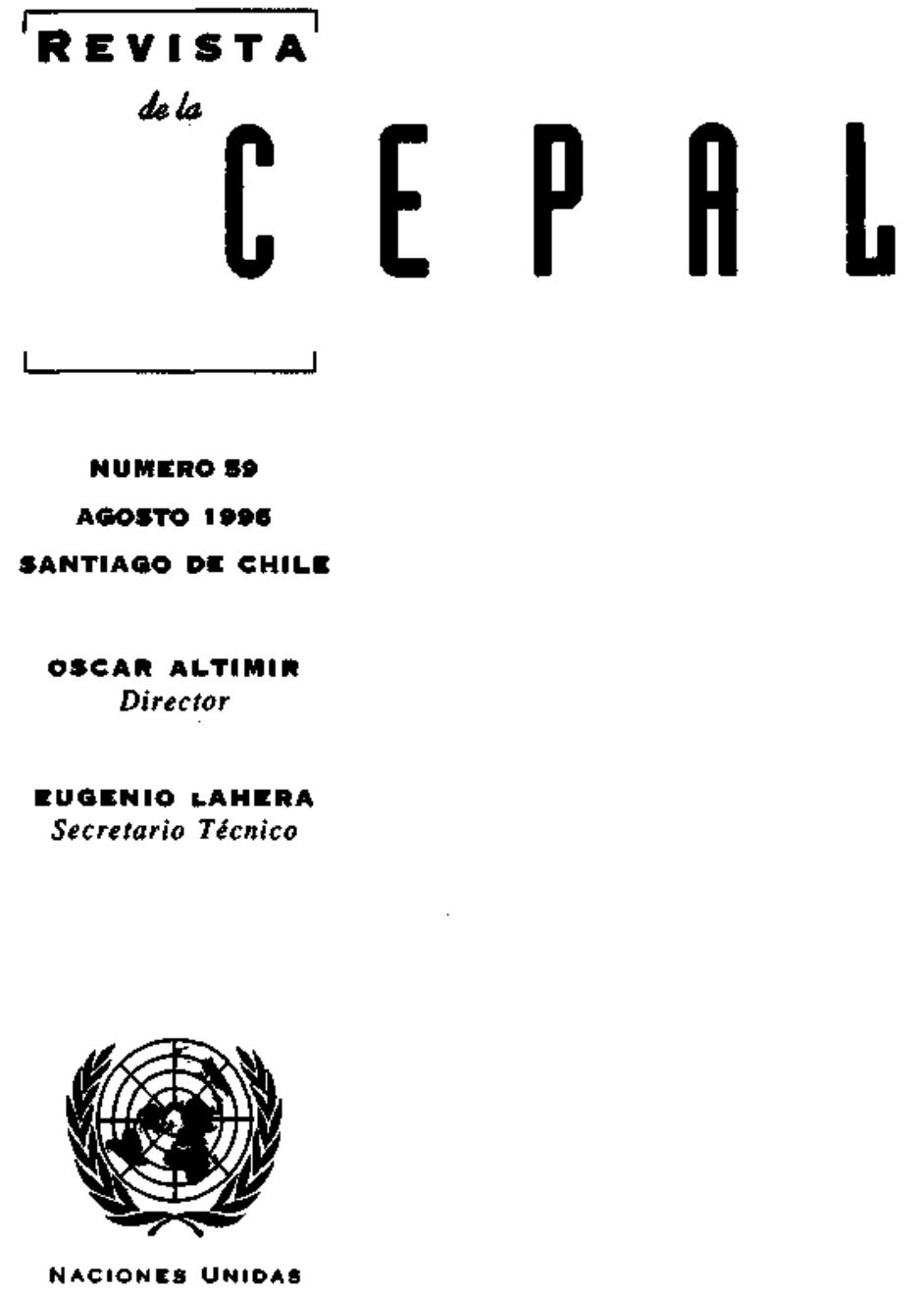


Interacciones entre macro y microeconomía

Gert Rosenthat

Politica económica, instituciones y desarrollo productivo en América Latina

Osvaldo Rosales

Competitividad sistémica: nuevo desafío para las empresas y la política

Klaus Esser, Wolfgang Hillebrand, Dirk Messner y Jörg Meyer-Stamer

La formación de habilidades báslcas y la capacitación para el trabajo productivo

Guillermo Labarca

Los fondos de inversión social en América Latina

Gabriel Siri

Mercados de derechos de agua: componentes institucionales

Miguel Solanes

Los países del Caribe y el área de libre comercio de las Amérlcas

Trevor Harker, Sidya Ould El-Hadj y Lucio Vinhas De Souza

La experiencia argentina: ¿desarrollo o sucesión de burbujas?

Hugo Nochteff

Posibilidades y límites de la reforma en la gestión de

la salud en Chile

Ana Sojo

Orientaciones para los colaboradores de la Revista de la CEPAL 


\title{
La experiencia argentina: ¿desarrollo o sucesión de burbujas?
}

\author{
A Fernando Fajnzylber
}

\section{Hugo Nochteff \\ Investigador del CONCET \\ y la Facultad Latinoamericana \\ de Ciencias Sociales (Flacso), \\ Argentina}

En este artículo se supone que el desarrollo es impulsado endógenamente por los mecanismos de innovación, de los cuales la elite económica es un portador privilegiado en la medida en que cumpla con eficiencia la función de generar innovaciones, buscando cuasi rentas tecnologicas que la competencia creativa erosiona permanentemente. A fin de que ello ocurra, deben darse las condiciones necesarias para que la búsqueda de cuasi rentas tecnologicas predomine sobre la de otros tipos de beneficios. La interacción de la elite económica argentina con el sistema institucional le permitió la obtención de cuasi rentas no tecnologicas, fundamentalmente cuasi rentas de recursos naturales escasos combinadas con cuasi rentas de privilegio. Esta interacción -que significó una restricción central al desarrollo a lo largo de Ja historia económica argentina- se profundiz 6 a partir de 1976 debido al debilitamiento de las instituciones y de gran parte de las organizaciones tras el golpe de Estado de ese afio, y a las políticas neoconservadoras que se aplicaron en los años siguientes. En los años noventa, el deterioro institucional y las políticas económicas inspiradas en las recomendaciones neoconservadoras de no injerencia estatal ("hands off") generalizada ampliaron las posibilidades de obtener cuasi rentas no tecnológicas y condujeron a una bur. buja liderada por el endeudamiento extemo y las privatizaciones. Antes de los procesos de privatización y desregulación, la existencia de oportunidades de lograr cuasi rentas que no provenían de avances tecnológicos y productivos habría desplazado a la innovacion y la inversion. Y posteriormente esos procesos -en un contexto de fragilidad institucional y extrema debilidad del sistema de pesos y contrapesos- habrian favorecido que tal desplazamiento continuara en los affos noventa. 
"Lo que no ha sido adecuadamente apreciado ... es la distinción entre diferentes tipos de reacción a los cambios de la condición. ... La interacción de las formas institucionales y la actividad empresarial ... es ... un tốpico fundamental para la investigación futura."

Joseph A. Schumpeter

\section{I}

\section{Introducción y síntesis}

El presente artículo postula como tesis central que las políticas aplicadas en Argentina en los años noventa, inspiradas en el neoconservadurismo, condujeron a una burbuja liderada por el endeudamiento y las privatizaciones, y no al desarrollo. Esta tesis se basa en el examen del período y en un conjunto de hipotesis sobre la interacción entre las instituciones y la elite económica, entendida ésta como el conjunto de agentes económicos que en cada período tuvo una posición dominante sobre el comportamiento del resto de los agentes económicos y una mayor influencia sobre las instituciones (Véase Nochteff, 1993 y 1994).

El concepto de cuasi renta se usa aquí como instrumento para analizar el comportamiento de la economía. Se considera que:

i) En un análisis estático la cuasi renta es análoga a la renta diferencial ricardiana; en términos dinámicos, e introduciendo el cambio tecnológico, las rentas ricardianas terminan siendo cuasi rentas en los casos en que la renta de escasez de un factor natural disminuye por la innovación tecnológica.'

ii) Las rentas ricardianas suelen ser - al menos en parte-cuasi rentas, en la medida en que su percepción está sostenida por instituciones que crean rigideces de oferta (como ocurrió con las barreras a la posibilidad de transar las semillas de caucho en el Brasil, con las instituciones del mercado de tierras en Argentina, o con las cláusulas de la Carta Magna sobre obstáculos en los cauces de los ríos en Inglaterra).

iii) La cuasi renta que se obtiene más por innovación que por otras rigideces de oferta es una cuasi

\footnotetext{
$\square$ Ëste artículo emanó de un proyecto de investigación patrocinado por la Fundación Volkswagen, que contó con la cooperación del Dr. Klaus Esser, del Instituto Alemán para el Desartollo, y en el que trabajaron Daniel Azpiazu, Eduardo Basualdo, Adolfo Vispo y el autor, quien es responsable de los posibles errores.

1 Véase un enfoque convergente, aunque mantiene el término renta, en Kaplinsky, 1995, p. 4
}

renta típica del desarrollo en sentido schumpeteriano y se ve erosionada desde el inicio por la competencia y la imitación (así, su transitoriedad es endógena al propio funcionamiento de la economía).

iv) Estas características la distinguen de las cuasi rentas facilitadas por barreras institucionales al ingreso (reservas de mercado, privilegios de financiamiento, subsidios), las que llamaremos cuasi rentas de privilegio, incluyendo entre ellas a las que surgen de la escasez de factores naturales acompañada de instituciones restrictivas.

v) Las cuasi rentas de privilegio no son cuasi rentas de desarrollo. Además, su transitoriedad no es endógena al funcionamiento de la economía, sino que puede perpetuarse tanto como duren la escasez de factores naturales, las instituciones restrictivas (de allí el uso en este ensayo del concepto de "posiciones monopólicas no (ransitorias"), o ambas cosas a la vez.

vi) Las cuasi rentas de privilegio alientan la formación de burbujas, porque elevan el valor de los activos por encima del equilibrio de largo plazo. Si bien no son "transitorias" en el sentido de verse erosionadas desde el inicio, en el largo plazo desaparecen porque la insuficiencia de innovación e inversión hace que sean desplazadas, ya sea porque las instituciones restrictivas no son suficientes para compensar el rezago y la baja productividad, o porque los segmentos de mercado que pueden preservarse con ellas se reducen hasta perder importancia para sus captadores (así sucede típicamente con las obtenidas por reservas de mercado en ramas dinámicas). ${ }^{2}$

\footnotetext{
${ }^{2}$ Sobre este tema, véase Napoleoni (1962, p. 1429 y siguientes), Schumpeter (1968); Kaplinsky (1995). La cuasi renta es análoga a un beneficio extraordinario (Ricardo, 1826). Se ha preferido el término cuasi renta para destacar la vinculación entre excedente presente y costo futuro en sentido marshalliano, y las barreras institucionales al ingreso.
} 
En resumen, lo que se postula es que la economía está en proceso de desarrollo sólo si las cuasi rentas tecnológicas predominan sobre los demás tipos de cuasi rentas. En caso contrario, los períodos de expansión son considerados "burbujas" con respecto al desarrollo apoyado en la innovación.

En la sección II se presentan -muy estilizadaslas hipótesis sobre las restricciones a la innovación (y en esa medida al desarrollo) en la Argentina, y se sostiene que esas restricciones deberían ser consideradas no tanto ofertas inadecuadas sino más bien demandas escasas de innovacion (y de políticas públicas que las promuevan). Esta escasa demanda habría sido causada por las formas en que interactúan las instituciones y organizaciones -especialmente las grandes empresas-, las que habrían permitido el logro de cuasi rentas no tecnologicas. Se argumenta que en las distintas etapas de la historia económica argentina, ni el sistema institucional ni las organizaciones habrían orientado a las elites económicas (en parte también distintas) hacia la búsqueda de cuasi rentas tecnológicas; por el contrario, la influencia de esas elites en las instituciones y organizaciones, ${ }^{3}$ les habría facilitado la obtención de cuasi rentas de privilegio. Esto habría sucedido tanto en la etapa agropecuaria/exportadora, como en la de industrialización sustitutiva de las importaciones. En la primera las cuasi rentas de privilegio se obtuvieron mediante la explotación extensiva de recursos naturales, las finanzas, la especulación en activos fijos (especialmente tierras) y financieros, el comercio y la explotación de los privilegios monopólicos concedidos por el Estado; estas actividades desplazaron la búsqueda de cuasi rentas tecnológicas (Nun, 1995; Sábato, 1988). En la segunda, se lograron en virtud de la estructura de tarifas efectivas, las reservas de mercado, y los subsidios directos e indirectos (véase Nochteff, 1994, p. 79 y siguientes, así como la bibliografía alli citada).

La sección III analiza el período posterior a 1976. Este período se asemeja a una nueva burbuja de obtención de cuasi rentas no tecnológicas, liderada básicamente por el endeudamiento externo. En él se distinguen tres fases. La primera corresponde a la de endeudamiento 1977-1981, que desembocó en la crisis de la deuda externa. La segunda abarca el decenio regresivo de 1980, en el cual la elite económica obtuvo cuasi rentas de privilegio a través de las transferen-

\footnotetext{
${ }^{3}$ Sobre la interacción de instituciones y organizaciones se ha seguido el enfoque de Burns y Dietz, 1995.
}

cias de ingresos a su favor (vía subsidios, licuación de sus pasivos -en especial externos-y compras estatales), en que se constituyeron mercados oligopólicos de bienes internacionalmente transables y no transables, y que terminó en las recesiones e hiperinflaciones del bienio 1989-1990. La tercera y última fase considerada, la burbuja 1991-1995, estuvo liderada por una combinación de endeudamiento externo, privatizaciones y algunas desregulaciones, y en ella se consolidaron las cuasi rentas de privilegio y tomaron creciente importancia las del trabajo barato. ${ }^{4}$ En esta sección se examinan también los principales efectos de largo plazo de lo sucedido en el conjunto del período - caracterizado por el predominio de los diagnósticos y recomendaciones neoconservadoras-y se argumenta con mayor detalle sobre el carácter regresivo para el desarrollo que tuvo la burbuja 1991-1995. Se supone que después de la liberalización del comercio el sector transable de la economía puede considerarse en general abierto y que, por lo tanto, el comercio exterior refleja adecuadamente los cambios en la estructura productiva; asimismo, se sostiene que las tendencias del comercio exterior dan importancia primordial a las ventajas comparativas, lo que indica un retroceso en términos de desarrollo y de competitividad (por lo menos de aquélla compatible con niveles ascendentes de bienestar y empleo). ${ }^{5}$

Se sostiene también que las políticas neoconservadoras aplicadas desde 1976, y especialmente en los años 1976-1983 y 1991-1995, reforzaron el comportamiento de la elite económica. Esto porque debilitaron muchas de las instituciones y organizaciones

\footnotetext{
${ }^{4}$ Llach (1987) observa que las cuasi rentas del trabajo barato -que denomina "lewisianas" por su vinculación con la oferta excedente de trabajo a salarios constantes - no fueron importantes en la historia argentina. Sin embargo, la caída de salarios reales a partir de 1976, a la mitad del valor de los años anteriores, y el enorme aumento de la desocupación y la subocupación a partir de 1992, cambiaron radicalmente el mercado de trabajo (Cortés, 1985, Minujin, 1993; Barbeito y Lo Vuolo, 1993), dando lugar a la obtención de rentas del trabajo barato. Las cuasi rentas "lewisianas" habrían aumentado durante la fase depresiva de la burbuja de 19911995. De acuerdo a las encuestas oficiales, "el $76 \%$ de los desocupados que buscan empleo to hacen sin interponer condicionante alguno, en términos de duración de la jornada laboral o de calificaciớn del puesto de trabajo" (Marcó del Pont, 1995) - y en consecuencia de salario real horario-r., lo cual es claramente lewisiano. ${ }^{3}$ Sobre la relación entre desarrollo, industrialización y perfil del comercio exterior, se han seguido en gran medida los enfoques de Klaus Esser sobre América Latina y los de Raphael Kaplinsky sobre los paises menos desarrollados, que coinciden fuertemente con el análisis de la economía argentina que se hace en este artículo (Esser, 1991; Esser, Hillebrand, Messner y Meyer-Stamer, 1993; Kaplinsky, 1993 y 1995).
} 
que tendían a limitar la influencia de esa elite sus posibilidades de obtener cuasi rentas políticas, y crearon reglas del juego que la favorecieron. ${ }^{6}$ Estas cuasi rentas elevaron los precios de los activos (fijos y en especial monetarios) y los programas de gasto muy por encima de los niveles de equilibrio de largo plazo y de información perfecta. Dichos presupuestos de gasto podrían haber sido sustentables si se hubiese producido un proceso de desarrollo, pero ese proceso no se produjo porque las cuasi rentas, que no estuvieron asociadas a la innovación ni a la producción, desplazaron a la inversión; en consecuencia, el aumento de la riqueza y su posterior caída sólo fueron fases de una burbuja.

Al respecto se ha afirmado que las políticas neoconservadoras distorsionaron los precios (Fanelli, Kacef y Machinea, 1995) y las rentabilidades relativas en favor de los sectores oligopólicos de bienes no transables, con efectos adversos sobre la competitividad de la economía; en definitiva, a pesar de la liberalización comercial, la economía tendió a cerrarse, y la elite económica integrada por los conglomerados económicos locales y los vinculados a empresas trasnacionales reforzaron su captación de cuasi rentas políticas. Así, debido a la debilidad de las instituciones y organizaciones, las reformas libremercadistas inspiradas en el pensamiento neoconservador no traspasaron la fijación de precios y rentabilidades del Estado al mercado, sino a un grupo reducido de grandes agentes económicos (Azpiazu y Vispo, 1995; Azpiazu, Bang y Nochteff, 1995). El debilitamiento de las instituciones del Estado (shock institucional) tuvo que ver fundamentalmente con los principios neoconservadores de no injerencia estatal ("hands off"), ${ }^{7}$ No se tuvo en cuenta que el

\footnotetext{
- Véase Azpiazu y Vispo, 1995; Azpiazu y Basualdo, 1995; Esser, 1991; Esser, Hillebrand, Messner y Meyer-Stamer, 1993; Basualdo, 1994.

${ }^{7}$ Se podría argumentar que las recomendaciones neoconservadoras (también llamadas neoliberales), y vinculadas por muchos autores al llamado Consenso de Washington, no se limitaban a las políticas seguidas en la Argentina. Sin embargo, como observa Platteau (1994, p. 534), la forma en que suele presentarse la receta implica o sugiere que el sistema de mercado puede suplantarse con éxito garantizado en cualquier suelo y en cualquier época. Esta despreocupacion por las especificidades de las instituciones, de las organizaciones y de las agencias llevo - en muchos paises de la región- a una forma de economía de libre mercado que ha dado pie a una despreocupada falta de regulación y orientación en todos los sectores de la economía (Esser, Hillebrand. Messner y Meyer-Stamer, 1993). En este sentido, puede afirmarse que el neoconservantismo fue el marco de inspiración de las políticas públicas de la Argentina, y de gran parte de la región (Krugınan, 1995; Nochteff, 1993).
}

desarrollo que "surge" desde el centro de la sociedad (el desarrollo endógeno) "es el mundo que supone de hecho la economía neoclásica, el que permite que sean válidas sus reglas de comportamiento y maximizacion. Pero es un producto histórico complejo, al que no se accede de la noche a la mañana" (Llach, 1987).

En Argentina no se había dado ese desarrollo que surge desde el centro de la sociedad, el desarrollo endógeno schumpeteriano. Por el contrario, los conglomerados locales más poderosos, ${ }^{8}$ que pasan a controlar la mayor parte de los activos privatizados y que son representativos de la elite económica, obtienen sobre todo cuasi rentas de privilegio. Así, el remezón institucional que significa el neoconservantismo afecta a una economía totalmente distinta de la supuesta por la teoría neoclásica en la que se inspira esa corriente, ya que el cambio "no se da de la noche a la mañana". En consecuencia, las estrategias de los conglomerados locales son totalmente distintas de las que emplean las empresas líderes, tanto de los países desarrollados como de las economías de industrialización reciente (EIR). ${ }^{9}$

En este sentido, el caso argentino sería un ejemplo extremo de lo ocurrido en los países grandes de la region. Antes de los procesos de liberalización y desregulación, la posibilidad de obtener cuasi rentas no provenientes de avances tecnológicos y productivos habría desplazado a la inversión en los dos primeros períodos de expansión mencionados. Luego, esos procesos habrían contribuido a que ese desplazamiento continuara en el pasado reciente.

En la sección IV se procura identificar y describir brevemente aquellos rasgos - no todos- del proceso de privatización y desregulación iniciado en 1991 (Azpiazu y Basualdo, 1995) que - de acuerdo con to expuesto en la sección III- contribuyeron a generar la burbuja de 1991-1995. En la sección V, por último, se resumen las conclusiones.

\footnotetext{
${ }^{8}$ La cúpula económica que creció a partir de 1976 (Azpiazu, Basualdo y Khavisse, 1987) y se consolidó en 1991-1995 (Azpiazu y Basualdo, 1995).

9 Compárense las estrategias, especialmente de diversificación, analizadas por Basualdo (1994) con las estudiadas por Hikino y Amsden (1995).
} 


\title{
II
}

\section{Desarrollo y tecnología en Argentina:}

\section{la expansión agropecuaria exportadora}

\author{
y la industrialización sustitutiva
}

\begin{abstract}
“...who made the discovery of the machine, or who first usefully applied it, would enjoy an additional advansage, by making great profits for a time but, in proportion as the machine [became]... of general use, the price of the commodity produced would. from the effect of competition, sink to its costs of production, when the capitalist would get the same money profits as before..."
\end{abstract}

David Ricardo

\section{1. ¿Desarrollo o burbujas?}

El desarrollo ${ }^{10}$ es impulsado por las innovaciones ${ }^{11}$ (y las inversiones asociadas a éstas) generadas por las empresas y los sistemas nacionales de innovación, de los cuales las primeras son parte y en los cuales la elite economica es un actor principal y decisivo (Dosi, Freeman, Nelson, Silverberg y Soete, 1988, parte II y V). Así, en gran medida, el desarrollo depende de que la elite económica cumpla eficientemente su función en el proceso que lleva a él. ${ }^{12}$ Esa función es la de obtener cuasi rentas tecnologicas, las cuales, mediante la innovación, crean posiciones monopólicas que la imitación creativa, la competencia y la difusión tecno-

\footnotetext{
${ }^{10}$ El terrmino desarrollo se usa aquí en sentido schumpeteriano, como contraposición a un proceso que tiende a un equilibrio estancado, salvo por factores exógenos a la economía misma (Schumpeter, 1968).

" En sentido amplio, que incluye la imitación creativa "baummoliana", el aprendizaje acelerado, los procesos de innovación de los usuarios, y las diferenciaciones de productos significativas para los beneficios y la estructura de los mercados (Schumpeter, 1968); Freeman, 1982).

12 Para evitar las confusiones usuales sobre el concepto de "empresario schumpeteriano", cabe recordar que Schumpeter (1957, cap. II) aclara que "no se ocupa de los factores concretos del cambio sino de los métodos por los cuales actúan éstos", es decir del mécanismo de cambio. El "empresario es simplemente el portador de ese mecanismo", y la ganancia originada en la innovación (cuasi renta tecnológica en los términos usados aquí) está presente en todo proceso de desarrollo, aun en uno en que el empresario haya sido sustituido por cualquier otro agente que cumpla la misma función (Schumpeter, 1968, cap. IV).
}

lógica erosionan permanentemente y convierten en necesariamente transitorias. En palabras de Javier Villanueva: cuando el monopolio de Schumpeter se crea, los perros de Walras comienzan a perseguirlo.

Para la elite económica, ésta es una "opción dura"13 en términos de tecnología, riesgo, inversión y cambio social. Para la sociedad, es lo que Napoleoni (1962), siguiendo a Schumpeter, denomina "renta de desarrollo", la cual tiende a un proceso de crecimiento endógenamente impulsado, en el que cada ciclo deja capacidades para generar otro ciclo de desarrollo endógeno (sobre la relación dinámica entre los ciclos véase Kalecki, 1965, y su interpretación en Nochteff, 1994. ${ }^{14}$

La economía argentina (como la mayor parte de las latinoamericanas) no parece haber seguido este sendero de desarrollo, sino uno adaptativo, de imitación tardía (tradicional en el sentido de Freeman, 1982). Su desempeño es un resultado magro del ajus-

\footnotetext{
${ }^{13}$ Sobre la distinción entre opción dura y opción blanda véase Esser, Hillebrand, Messner y Meyer-Stamer, 1993. En un sentido convergente, Kaplinsky (1995) distingue entre lo que él llama el high road y el low road en el desempeño económico, según el tipo de renta que se obtiene ("de recursos naturales", "de habilidad". "de recursos humanos").

${ }^{14}$ En la tradición de la dinámica económica evolucionista, estos conceptos están asociados más con la idea de desequilibrio sostentdo que con la de alternancia entre periodos de desequilibrio/desarollo y de equilibrio estacionario. Al respecto véase la dinámica ć́clica expuesta por Kalecki (1965) y su comparación con el desarroilo schumpeteriano en Nochteff (1994).
} 
te pasivo a estímulos exógenos u oportunidades externas creadas por otras economías. La elite económica argentina $^{15}$ se adaptó - $-y$ en buena medida forzó la adaptación de las instituciones- a esas oportunidades, y se mantuvo protegida de la competencia a través de posiciones monopólicas no innovadoras ni transitorias, sostenidas por políticas gubernamentales y barreras institucionales al ingreso, obteniendo así cuasi rentas de privilegio. Para la elite económica, ésta es una "opción blanda" en los términos descritos. Para la economía, no es un proceso de desarrollo, sino más bien una sucesión de períodos de auge, o burbujas, ${ }^{16}$ más compatibles con el estancamiento de muy largo plazo (en comparación con las economías que se desarrollan) que con un sistema de instituciones, organizaciones y fuerzas productivas aptas para generar el desarrollo.

En los procesos de desarrollo, debido al predominio de la búsqueda de cuasi rentas tecnológicas, las políticas e instituciones promotoras de la ciencia, la innovación, la industrialización y la inversión tienen una enorme importancia en las agendas de los gobiernos, las elites económicas y el conjunto de la sociedad; y los esfuerzos en ciencia y tecnología están directamente vinculados a los patrones de producción, inversión y comercio exterior. En una economía como la argentina, de tipo adaptativo, imitativo tardío o "tradicional", todas estas cuestiones son secundarias en esas agendas, y los esfuerzos científicos y tecnológicos están débilmente vinculados a dichos patrones. La obtención de cuasi rentas de privilegio (y de rentas ricardianas) es lo que hace que esta debilidad se deba menos a una oferta inadecuada de ciencia y tecnología que a una demanda efectiva insuficiente de ellas (Cereijido, 1990). ${ }^{17}$ En síntesis, esta insuficiencia de demanda está directamente vinculada al comportamiento (la elección

\footnotetext{
15 Los ternas examinados en esta sección se tratan en detalle en Nochteff, 1993 y 1994.

${ }^{16}$ En este articulo también se consideran burbujas algunos períodos largos i) cuando el aumento de la riqueza y el valor de los activos en uno de esos períodos es superior al sustentable por el aumento de la inversión, la productividad y la composición de la producción y del comercio exterior, y ji) cuando dejan sistemas institucionales y económicos muy poco eficientes para un proceso de desarrollo. Esto no significa ignorar que dentro de cada período pueden ocurrir burbujas en el sentido más usual del término.

${ }^{17}$ Con predominio de cuasi rentas de privilegio, la recomendación neoconservadora sobre ciencia y tecnología tiene un efecto especialmente perverso. Cuando se aconseja que el esfuerzo en este campo se oriente exclusivamente por la demanda empresaria, se yerra por asumir que las firmas tienen información tecnologica perfecta (Bessant, 1991); y si además la elite económica busca cuasi rentas no tecnologicas, el error se multiplica.
}

y obtención de opciones blandas) de la elite económica, que guarda relación con la ineficacia de las instituciones para el crecimiento de largo plazo, y con la debilidad de los controles y contrapesos sociales y políticos que podrían influir en él, limitarlo o cambiar10. 18

\section{Las opciones blandas: una visión retrospecti- va}

\section{a) La expansión 1880-1914}

Como se sugirio más atrás, la primera opción blanda para la elite económica argentina fue el ciclo de expansión -o mejor, la burbuja- liderada por la exportación primaria y la expansión de la frontera agropecuaria. La combinación de las ventajas comparativas "naturales" con los cambios tecnológicos y económicos de las economías europeas; las imperfecciones de mercado (tal como la inexistencia de un mercado mundial de tierras); las barreras institucionales al ingreso (la legislación local de tierras y de arriendos, los sistemas de financiamiento de la adquisición de tierras y de producción agropecuaria), y los privilegios concedidos por el Estado, permitió que la elite economica de ese período obtuviera rentas ricardianas combinadas con cuasi rentas de privilegio y ampliadas por ellas. Así, se consolidó un sistema institucional y un tipo de comportamiento de la elite económica que parece haber perdurado pese a los cambios en la economía argentina e incluso en la composición de buena parte de dicha elite. Ese comportamiento puede caracterizarse por una gran capacidad de adaptación -de tipo especulativo - para aprovechar oportunidades de obtener cuasi rentas de privilegio, de ejercer una fortísima influencia sobre las instituciones y las políticas públicas - que hace posible la obtención de esas cuasi rentas-m, y de rápida diversificación y cambio de actividad. Esta capacidad es la contracara de un bajo perfil en materia de inversión, innovación tecnologica, eficiencia productiva y especialización (Sábato, 1988).

\section{b) La industrialización}

El estilo de industrialización argentino, especialmente a partir de la crisis de los años treinta que terminó con la primera gran burbuja, resultó en gran medida del comportamiento y de las actitudes de la elite económica tradicional (Nochteff, 1994, pp. 52-74), a

\footnotetext{
${ }^{18}$ Véase un estudio de caso sobre el fracaso de las políticas públicas en un contexto así, en Nochteff, 1995.
} 
la que, especialmente después de los años cuarenta, se incorporaron las empresas transnacionales industriales, dando lugar a la industrialización sustitutiva de las importaciones liderada por estas empresas. Dicha industrialización constituyó la segunda gran opción blanda para la elite económica y llevó a una segunda "gran burbuja" de la economía argentina, que acentuó sus características de adaptación y de imitación tardja, y creó nuevas restricciones al desarrollo.

La industrialización sustitutiva de las importaciones condujo a una estructura de productividades heterogénea o enfermedad holandesa evolutiva, ${ }^{19}$ debido al camino por el cual se optó - la "opción proteccionista".-, en gran medida por la influencia de algunas fracciones de la cúpula empresaria local y de las empresas transnacionales. ${ }^{20}$

En términos sumamente estilizados, las características principales de la enfermedad holandesa evolutiva son las siguientes:

i) Hay una diferencia importante entre los costos marginales del sector primario y del sector industrial ${ }^{21}$ (en realidad, entre los de los sectores con ventajas comparativas "naturales" y aquéllos con ventajas comparativas construidas por el hombre). Los costos marginales no aumentan de modo continuo desde algunos sectores primarios a otros, y luego desde unos sectores industriales a otros, sino de modo discreto (hay uno

${ }^{19} \mathrm{El}$ nombre de enfermedad holandesa evolutiva ha sido usado por Schydlowsky (1993), aunque el fenomeno fue analizado ya en los años sesenta por Oscar Braun y por Marcelo Diamand (que lo denominó "estructura productiva desequilibrada"). Posteriormente, ha sido estudiado por diversos economistas, como Mallon y Sorrouille (1976), Diamand (1988) y Heymann (1984), quien además presenta un modelo capaz de explicar con notable precisión los aspectos macroeconomicos de la burbuja 1991-1995.

20 Nochteff (1994) analiza el juego de instituciones, actores, limitaciones y oportunidades que jlevó a que la elite economica apoyara el sendero de la industrialización sustitutiva liderada por empresas transnacionales, al que se denomina "opción proteccionista", como distinta de las opciones "ortodoxa", "devaluatoria", e "industrial exportadora" o de "neutralidad ampliada". Esta tiltima, sostiene, fue la seguida por las economías exitosas del Sudeste asiático. 21 Es muy importante tener en cuenta que, para simplificar, se incluye en el sector primario a las actividades primarias e industriales ligadas muy directamente a ventajas comparativas dadas por recursos naturales, y en el sector industrial a las actividades productoras de bienes mas diferenciados, en las que el trabajo muy catificado tiene alta incidencia en el costo y la competitividad está muy asociada a la capacidad propia de innovación (incluida la rápida imitación creativa). Así, en esta clasificación se hallarían en el sector primario las refinerías de petróleo, la producción de aceites vegetales para venta a granel y la de leches comunes, e incluso la petroquímica y la sidenurgia básicas; y en el industrial la producción de bienes de capital, la química fina, la producción de quesos, leches y aceites comestibles de alto precio para exportación, la de aceros especiales y los servicios siderúrgicos. o más "escalones" en los costos marginales comparados).

ii) El tipo de cambio tiende a colocarse (en parte debido a las políticas económicas que se aplican) en torno a lo que puede llamarse la paridad de costos del sector primario.

Debido a esos dos hechos, los costos y precios monetarios del sector industrial fueron más altos que los internacionales, y las actividades industriales crecieron porque trabajaban con un tipo de cambio exclusivamente para importaciones cercano a la paridad de costos de la industria, formado por subsidios arancelarios y no arancelarios.

Como el tipo de cambio de exportación no se ubicaba en torno a la paridad de costos del sector industrial (las tarifas efectivas de exportacion no eran equivalentes a las de importacion), ${ }^{22}$ los sectores industriales no exportaban (en términos muy estilizados). La economía estaba formada básicamente por dos sectores: el productor y exportador de bienes transables (el primario) y el productor de bienes no transables que demandaba divisas (el industrial más el terciario).

Estos comportamientos tienen efectos muy amplios. En primer lugar, impulsan una economía cerrada, es decir, una economía en la que el sector productor de bienes transables es pequeño. Esto lleva a que la mayor parte de la economía eluda la competencia internacional, facilitando así que los grandes agentes económicos obtengan cuasi rentas de privilegio, amparados en posiciones monopólicas no transitorias.

En segundo lugar, la oferta de divisas por las exportaciones del sector primario sólo permite el equilibrio en condiciones de estancamiento y alto desempleo. En términos simplificados, si se pretende que el sector no transable (industrial más terciario) crezca más que las exportaciones primarias se cae en una restricción externa. Si la restricción se cubre temporalmente con endeudamiento, se aumenta aún más la demanda de divisas futuras (servicios de la deuda) para -a igualdad de otras condiciones- el mismo nivel de exportaciones, lo que empeora el problema. Esto llevó a la economía a un funcionamiento de "arranque y parada" (Diamand, 1988; Heymann, 1984).

En tercer lugar, el desempeño microeconómico en el sector industrial depende fuertemente de las políticas cambiarias y comerciales. En general, los cambios

\footnotetext{
${ }^{22}$ A diferencia de lo que ocurrió en las EIr, en las cuales el llamado sistema de neutralidad ampliada tendió a aproximar la rentabilidad de las ventas al mercado interno con la de las exportaciones.
} 
en la paridad y en la política comercial son mucho más importantes para las empresas que casi cualquier cambio tecnológico. Los esfuerzos tecnológicos no apuntan a alcanzar la frontera de las mejores prácticas, sino a ajustes relativamente menores de tecnologías existentes (y en general atrasadas) introducidas en gran parte a través de la importación de insumos y de bienes de capital (en buena parte usados o más o menos obsoletos). Los senderos de aprendizaje tienden a tomar la forma de esfuerzos tecnológicos para adecuarse a las limitaciones (de escala, de disponibilidad de insumos, de proveedores o de infraestructura) de una economía industrial cerrada, producidas por la misma enfermedad bolandesa evolutiva, y no eliminan los "escalones" de costos marginales, reproduciendo así dicho mal.

En cuarto lugar, las políticas comerciales, cambiarias, de subsidios y de concesión de reservas y cuasi reservas de mercados, y en general todas las que permiten obtener, preservar o distribuir las cuasi rentas de privilegio y las rentas ricardianas, son centrales en la agenda de la elite económica, de los gobiernos y de la sociedad. Así, las políticas orientadas a fomentar la innovación, el aprendizaje de las mejores prácticas, la inversión y el aumento de la productividad son desplazadas a posiciones muy secundarias.

Por último, no existe sinergia entre el sector primario y el industrial, se desaprovechan las ventajas comparativas dinámicas y también las estáticas, y el sector primario se rezaga y no avanza hacia productos más diferenciados, en comparación con otras economías (Esser, Hillebrand, Messner y Meyer-Stamer, 1993).

En resumen, la industrialización sustitutiva de las importaciones fue para la elite económica una suerte de "gran burbuja"23 impulsada por la obtención de cuasi rentas no tecnológicas y resultante de la interacción entre el sistema institucional y la elite económica (y otras organizaciones y actores), antes que un proceso de desarrollo en sentido schumpeteriano. Por el contrario, la enfermedad holandesa evolutiva creó nuevas restricciones al desarrollo, de índole económica, tecnológica, institucional y organizacional. ${ }^{24}$

\section{III}

\section{La corriente neoconservadora y la burbuja} liderada por el endeudamiento

Aun con las limitaciones de la industrialización sustitutiva, durante el último período de ella (y especialmente entre 1964 y 1974) hubo un proceso de industrialización dinámico: en el decenio indicado el crecimiento del pIB per cápita fue el mayor del siglo y el de menor rezago en relación con otros países (Sorrouille y Lucángeli, 1980; Llach, 1987). ${ }^{25}$ Ese dinamismo

\footnotetext{
${ }^{23}$ Porque -especialmente durante las fases de arranque-- mantuvo los valores de las rentabilidades y los activos del sector no transable (industria más servicios) por encima de los de largo plazo. Como ya se dijo, esto comporta una estilización en la que una serie de burbujas se asimilan en una sola según los factores que las impulsan.

${ }^{24}$ Este fenomeno fue especialmente nítido en el periodo de industrializacion sustitutiva de las importaciones anterior a las "correcciones parciales" de la década del sesenta (Nochteff, 1994). Por elto, la década de 1950 fue la de mayor atraso relativo, en términos de producto bruto por habitante, del período 1929-1983 (Llach, 1987).

25 Sobre la industrialización sustitutiva en su conjunto y en este perfodo en especial, véase Malion y Sournouille, 1976.
}

se debió en gran parte a los procesos de aprendizaje, a la corrección parcial del sendero proteccionista y al empate sociopolítico que ponía límites a la elite económica y al crecimiento de la industria y el comercio mundiales (Nochteff, 1994). La crisis política y económica de 1975 y el golpe militar de 1976 rompieron ese empate y la elite económica recuperó el poder deteriorado parcialmente durante la industrialización sustitutiva.

\section{El neoconservadurismo y la gran burbuja en tres períodos \\ a) 1977-1981}

A partir de ese momento, la elite económica for$z 6$ otro período de opciones fáciles y de obtención de cuasi rentas de privilegio. Desde el punto de vista del factor que lo lidero, el endeudamiento externo, este período puede considerarse una única "gran burbuja". Sin embargo, conviene distinguir tres etapas. Durante 
la primera, básicamente entre 1977 y 1981, la elite económica aprovech6 la oportunidad dada por el aumento de la liquidez y la baja de las tasas de interés en el mundo. Durante este péríodo, las cuasi rentas de privilegio se concentraron en la actividad financiera (Basualdo, 1987), y en sectores de bienes no transables protegidos en medio de una fuerte liberalización comercial. Por otra parte, comenzó a crecer la importancia de las cuasi rentas del trabajo barato.

\section{b) 1982.1990}

En una segunda fase, después de la crisis de la deuda externa que acabó con la primera burbuja (19771981), los conglomerados lograron mantener cuasi rentas de privilegio obteniendo transferencias de ingresos masivas a través de distintos tipos de subsidios (Azpiazu y Basualdo, 1987; FMI, 1986). Así, crecieron durante el decenio regresivo de los ochenta, y acumularon el capital y el poder económico que luego les permitió aprovechar la burbuja liderada por el endeudamiento externo y las privatizaciones en los años noventa. Por otra parte, este funcionamiento contribuyó de manera decisiva a la crisis fiscal que disparó las recesiones e hiperinflaciones de 1989-1990.

\section{c) De 1991 en adelante}

A partir de 1991, y al repetirse casi el fenomeno de alta liquidez y bajas tasas de interés en el mundo, resurgió la burbuja iniciada hacia 1976-1977. Esta vez las políticas neoconservadoras tuvieron mucho más peso, porque la combinación del endeudamiento externo con las privatizaciones, la desregulación y la liberalización comercial contribuy 6 a que pudieran obtenerse cuasi rentas no tecnológicas.

\section{Una revisión del desempeño económico en el período posterior a 1976}

El desempeño de la economía desde el quiebre de la industrialización sustitutiva puede medirse de manera sumaria del modo que sigue. ${ }^{26}$

El producto por habitante en 1995 fue $12.7 \%$ inferior al de 1974. La inversión bruta fija en 1995 fue el $18.6 \%$ del P1B, y un $3.6 \%$ inferior a 1974 .

El salario medio real fue en 1993 un $51.2 \%$ infe-

${ }^{26}$ Los datos que se usan en este apartado y en el siguiente se elaboraron sobre la base de Azpiazu y Nochteff (1994a), FIDE (1996), FEL (1996), Argentina, Ministerio de Economía y Obras y Servicios Públicos (1995) y CEPAL (1995). rior al de 1974 y aunque no existen datos sobre su evolución posterior, se estima que en 1995 fue aún más bajo.

En lo que se refiere a la ocupación, entre 1974 y 1995 la tasa de desempleo abierto creció un $411.8 \%$ (de $3.4 \%$ a $17.4 \%$ ) y la de subempleo visible pas 6 del $5.4 \%$ al $12.0 \%$.

En cuanto a la distribución del ingreso, en 1995 la participación de los cuatro primeros deciles era un $28 \%$ inferior a la de veinte años antes; la de los cuatro deciles siguientes, un $11.6 \%$ inferior, y la de los dos deciles de mayores ingresos un $24.4 \%$ superior. El decil que más perdió en el período fue el de menores ingresos $(41.9 \%)$ y el que más ganó, el de ingresos más altos $(43.5 \%)$. Si se considera el PIB por habitante, la pérdida absoluta del decil más pobre fue del $52 \%$ y la ganancia absoluta del decil más rico del $29 \%$.

La pobreza creció del $4 \%$ al $20 \%$ (es decir, $600 \%$ ) entre 1974 y $1992-1993$.

El grado de apertura de la economía (X=M/PIB) en 1995 fue de aproximadamente $15 \%$, alrededor de $7 \%$ inferior al $16.2 \%$ de 1973 . La relación X/Pts cayó un $16.7 \%$ (de $9.6 \%$ en 1973 a aproximadamente el $8 \%$ en 1995).

La vulnerabilidad externa (relación entre la deuda externa y las exportaciones) habría aumentado un $164.3 \%$. En 1974 la deuda externa pública equivalía a 1.4 años de exportaciones; en 1995 la deuda externa pública financiera equivalía a 3.7 años de exportaciones (una relación $200 \%$ mayor que la del conjunto de los países en desarrollo). ${ }^{27}$

En resumen, la involución económica y social de la Argentina en el período posterior a 1976 fue, por decir lo menos, muy grave. ${ }^{28}$

\section{Elementos para el análisis de la burbuja 1991- 1995}

Favorecida por la situación financiera mundial, la aplicación de políticas neoconservadoras de reducción del papel del Estado, la crisis económica, la extrema debilidad institucional -agravada por las hiperinfla-

\footnotetext{
${ }^{27}$ Las estimaciones sobre la deuda externa pública financiera en 1995 son muy variables. Se ha optado por seguir los cálculos de Machinea, 1996.

${ }^{28} \mathrm{La}$ comparación "entre puntas" puede dejar alguna duda, pero cabe señalar que en todos los casos el ajuste a rectas por mínimos cuadrados de los datos anuales del período confirma que se trata de tendencias de largo plazo (Azpiazu y Nochteff, 1994a, gráficos la 6 ).
} 
ciones y el deterioro de las organizaciones-,$-{ }^{29}$ la elite económica concentrada aprovechó una nueva burbuja, esta vez liderada por el endeudamiento externo, las privatizaciones y la desregulación, dentro de la cual extremó y consolidó la obtención de cuasi rentas de privilegio y lewisianas.

La combinación de las altas tasas de interés en pesos, ${ }^{30}$ el tipo de cambio fijo y la liberalización financiera empujaron —como en la burbuja 1977-1981el ingreso masivo de capitales. El grueso de estos capitales fue usado: i) para financiar las adquisiciones de empresas públicas por los conglomerados, de los cuales los vinculados al proceso de privatización contrajeron en 1990-1994 el 77\% de la deuda extema privada (Basualdo, 1994); ii) para financiar un auge del consumo, especialmente del suntuario, como se puede presumir por la distribución del ingreso y la baja propensión al ahorro, inferior incluso a la propensión a la inversión, dada la fuerte entrada de capitales; en 1991 1994 la relación consumo/PIB fue del $82.1 \%$, en tanto que la relación entre la inversión bruta y el PIB fue de sólo $17.4 \%$ (el valor máximo, en 1994, fue del $20 \%$, y en 1995 la cifra cayó abruptamente).

La afluencia de capitales y la inflación en los bienes no transables -impulsada por el consumo y por las altas tarifas de los servicios públicos privatizadosapreciaron la moneda. Combinadas con una brusca liberalización comercial, erosionaron fuertemente la competitividad, y desplazaron las mejoras de los precios y de las rentabilidades relativas, así como la poca inversión, hacia el sector de bienes no transables (Fanelli, Kacef y Machinea, 1995; Kacef, 1994; Coloma, 1993).

Tanto la inversión interna como la inversión extranjera directa (IED) se orientaron a compras y reestructuraciones de empresas y, en menor medida, a la construcción de plantas nuevas. Los principales destinos de la inversión fueron los servicios públicos privatizados y la producción para el mercado interno o, eventualmente, la complementación dentro del Mercosur. Las inversiones en nuevas plantas de bienes transables ocuparon un lugar secundario, concentrándose en la extracción y producción de bienes exportables poco diferenciados, básicamente productos mineros, gas y petróleo, productos agrícolas y manufacturas simples

\footnotetext{
${ }^{29}$ Estatales, sindicales, políticas y representativas del empresariado. ${ }^{30}$ El comportamiento monetario no fue totalmente endogeno: las políticas financieras y fiscales tendieron a elevar las tasas de interés.
}

de origen agropecuario (sobre la IED, véase Chudnovsky y Lopez, 1994). En los sectores industriales que mejoraron más los precios y la productividad, la exportación siguió siendo básicamente anticíclica, el mercado se hizo oligopólico, y las inversiones -tanto las realizadas como las proyectadas - no parecen suficientes para mantener la competitividad (véase, por ejemplo, Azpiazu y Nochteff, 1994b).

La desregulación -en un contexto institucional y organizativo muy débil, sin legislación ni agencias antimonopolios efectivas, y durante un proceso de privatización en el cual se enajenaron algunas de las empresas más grandes- no trasiadó la fijación de precios y rentabilidades y la asignación de recursos del Estado al mercado, sino principalmente a un grupo de conglomerados interrelacionados (Azpiazu y Basualdo, 1995). El marco institucional y organizacional de las privatizaciones no sólo no condujo a una mayor competencia, sino que de hecho trabó los mecanismos del mercado. (Véase Azpiazu y Nochteff, 1994a, pp. 157 a 221; Azpiazu y Basualdo, 1995).

Consecuentemente, la economía, a pesar de una liberalización cambiaria muy profunda (UNCTAD, 1995), tendió a cerrarse: la relación X+M/PIB en 1991-1995 estuvo en torno al $13 \%$ a $14 \%$, una de las más bajas de la historia argentina: en el quinquenio anterior había sido de $15.8 \%$ (FIDE, 1996) y en 1969-1973, en plena sustitución de importaciones, de $16.8 \%$.

En esta economía cerrada y oligopolizada, los conglomerados que forman el centro de la elite económica se desplazaron aún más hacia mercados monopólicos u oligopólicos de bienes no transables al amparo de la competencia externa e interna, aumentando y consolidando su capacidad de obtener cuasi rentas de privilegio y apartándose cada vez más de la estructura y el comportamiento de los conglomerados de economías dinámicas. En 1994, el último año de expansión de la burbuja, casi el $40 \%$ de las utilidades totales de las 20 firmas con mayor cuantía de utilidades se obtuvo en sectores monopólicos o duopólicos de servicios públicos privatizados no transables; otro $45 \%$ se obtuvo en actividades oligopólicas de explotación de recursos naturales no renovables (gas y petróleo) y sólo en torno del 13\% en la industria (Gaggero, 1995).

En 1994, la burbuja "implotó". El disparador fue el "efecto tequila" pero la causa principal fue la extrema fragilidad externa de la economía. ${ }^{31}$ Esta se puede

${ }^{31}$ Para el análisis macroeconómico de la burbuja, véase Fanelli, Kacef y Machinea (1995). 
apreciar por: el creciente desequilibrio del comercio exterior (que pasó de un superávit de 8274 millones de dólares a un déficit de 5752 millones entre 1990 y 1994); la caída de la relación X/PIB (del $11.9 \%$ en 1990 al $5.7 \%$ en 1994); el aumento del déficit de cuenta corriente (se multiplicó por 40 entre 1991 y 1994); la elevadísima relación entre la deuda externa y las exportaciones, y el aumento de la deuda pública externa neta en un monto equivalente al $109.5 \%$ de las exportaciones de 1994 (Poli y Peirano, 1996), a pesar del Plan Brady y de que en el período ingresaron 27000 millones de dólares por privatizaciones. (Según Machinea, 1996, "es como si una empresa hubiese aumentado su deuda al tiempo que vendía sus activos").

Una burbuja en un sistema de tipo de cambio fijo con convertibilidad que se asemeja al patrón oro, no explota sino que "implota". Hasta ahora, el indicador más confiable de la "implosión" es la tasa de desempleo. Durante el crecimiento de la burbuja, la expulsión de mano de obra de los sectores de bienes transables y de las empresas públicas privatizadas fue encubierta por el surgimiento de trabajadores por cuenta propia que utilizaron sus indemnizaciones por despido para financiar actividades inviables, $y$ muy parcialmente compensada por el auge del sector de bienes no transables: el desempleo abierto pasó del $6.9 \%$ en 1991 al $10.7 \%$ en 1994. Cuando se produjo la "implosión", la mano de obra expulsada del sector no transable se sumó a la del transable y al agotamiento de los fondos provenientes de las indennizaciones; la cifra llegó a $18.6 \%$ en 1995 , es decir, subió $73.8 \%$ en un año (Kacef, 1994), en situación de plena flexibilidad laboral y de oferta de trabajo con salarios y condiciones decrecientes (Marcó del Pont, 1995).

Todo lo anterior confirma tres puntos: i) las politicas económicas inspiradas en el neoconservantismo, unidas a la fragilidad institucional, a la debilidad de los controles y contrapesos políticos y sociales, y al comportamiento de la elite económica, condujeron a una burbuja y no a un proceso de desarrollo; ii) la elite económica presionó la burbuja para obtener cuasi rentas de privilegio, cuasi rentas lewisianas (especialmente a partir de 1994) y, en parte, rentas de recursos naturales no renovables (las cuales, en los términos de este artículo, y dada la importancia de las concesiones estatales en estas actividades, son en parte cuasi rentas de privilegio).

En consecuencia, las políticas y los esfuerzos para obtener cuasi rentas de desarrollo están aun más relegados que antes. Uno de los indicadores de la importancia que se les asigna es el gasto en ciencia y tecno- logía. La participación de éste en el gasto público cayó de un escasísimo $0.27 \%(1980-1987)$ a un $0.24 \%$ en los años noventa, y su participación en el PIB se ha reducido sistemáticamente desde 1992. En 1994, el gasto total en investigación cientifica y tecnológica era un $0.29 \%$ del producto, un porcentaje 10 veces menor que el de los países desarrollados, y entre 4 y 7 veces menor que en el de las EIR asiáticas (Chudnovksy y Lopez, 1995).

\section{Burbuja, cuasi rentas de privileglo y estructu- ra productiva}

En una economía cerrada y con baja competitividad, ${ }^{32}$ las exportaciones tienden a seguir un comportamiento anticíclico: con la implosión las exportaciones crecieron un $46 \%$ en el primer trimestre de 1995. Como podía esperarse, el aumento no está vinculado a una mayor penetración en economías abiertas y desarrolladas, ${ }^{33}$ sino que fue inducido por la caída de la demanda interna -que impulsó aumentos de las unidades exportadas--, el alza de precios de los productos básicos y la recuperación de la economía brasileña combinada con la apreciación del real. Casi un $52 \%$ del aumento de las exportaciones totales y un $75 \%$ del de las industriales fueron al MERCosur, fundamentalmente a Brasil (Porta, 1995).

Sin datos disponibles sobre el PIB por ramas, y después de la liberalización comercial, la estructura del comercio es un buen reflejo del desempeño tecnoproductivo: i) la balanza comercial sólo tuvo superávit cuando se produjo la "implosión" y se dieron condiciones exógenas favorables (y frágiles), y ii) se asignó gran prioridad al aprovechamiento de las ventajas comparativas.

Mientras otros países de la región están entrando en la "segunda fase exportadora" de economía abierta (Díaz, 1995), la Argentina tendió a retroceder hacia una economía más cerrada y una "primera fase exportadora". Según Beckerman y Sirlin (1996) las ventajas comparativas reveladas (VCR) por el comercio exterior argentino indican que en el período éstas cayeron en las actividades manufactureras respecto de las primarias (especialmente aquéllas vinculadas a los recursos naturales no renovables); en las actividades

\footnotetext{
32 Véase un análisis coincidente de la competitividad en Messner y Meyer-Stamer (1994).

33. Al respecto, es impotante señalar que hacia 1993-1994 la Argentina tenía sólo 30 empresas con certificados de calidad ISO 9000 , en tanto que Brasil tenía 500 .
} 
manufactureras de origen industrial en relación con las de origen agropecuario, ${ }^{34} \mathrm{y}$ en las actividades de mediana y en especial de alta tecnología respecto de las actividades industriales tradicionales con insumos de uso difundido (no diferenciados) y de baja tecnología. A su vez, se redujeron las ventajas comparativas de las actividades manufactureras en relación directa (aunque no proporcional) con su utilización de trabajo calificado (Bisang, 1995).

En conjunto, los análisis del comercio exterior muestran una fuerte regresión tecnológica e industrial, ${ }^{35}$ coherente con las tesis de este artículo y en especial con la del creciente desplazamiento de la elite económica hacia el sector de bienes no transables, y hacia la obtención de cuasi rentas de privilegio, lo que impone nuevas restricciones al desarrollo.

\section{Observaciones sobre el proceso de privati- zación y desregulación}

El proceso de privatización y desregulación ${ }^{36}$ tal como se llevó a cabo en Argentina fue una de las piezas claves de la aplicación de las políticas inspiradas en el pensamiento neoconservador, de la burbuja 19911995 y de la obtención de cuasi rentas de privilegio. ${ }^{37}$

Este proceso fue el principal en materia de reforma del Estado. En cambio, en los países de la Organi-

\footnotetext{
34 Beckerman y Sirlin (1996) muestran que entre 1990 y 1994 las exportaciones de bienes primarios incrementaron un $60 \%$ su aporte positivo a las VCR, las manufacturas de origen agropecuario un $10 \%$, y las exportaciones de energeticos pasaron de representar una proporción insignificante del comercio a un aponte relativo cercano al $12 \%$ de las vCR positivas. Mientras tanto, el aporte negativo de las manufacturas de origen industrial a las vCR crecio 1.5 veces. Estos resultados se agravan porque las manufacturas de origen agropecuario no tienden a formar conglomeraciones tecnológico-productivas. Por ejemplo, mientras en el Brasil los subproductos de la extracción de aceites vegetales se han usado para el desarrollo de una industria avícola intensiva, Argentina los exporta como "residuos de la industria alimenticia" (uno de los principales rubros de exportación del país).

35 En Cepeda (1995a y b) pueden verse resultados convergentes a partir de distintas metodologías.

${ }^{36}$ En esta sección se identifican algunos de los rasgos del proceso de privatización y desregulación que contribuyeron a la burbuja 199l-1995 y a la obtención de cuasi rentas de privilegio. En consecuencia, no es ni debe tomarse como un balance de dicho proceso. Así, aquí no se analiza la mejora sustancial en la prestación de servicios ni otros aspectos de la desregulación (por ejemplo, el aumento de la competencia en mercados como los de servicios profesionales o la reducción de costos de servicios como los portuarios). Tampoco se analiza el fuerte aumento de los precios de la mayor parte de los servicios públicos privatizados (Azpiazu, Bang y Nochteff, 1995).

${ }^{37}$ Esta sección está basada en Azpiazu y Vispo (1995); Azpiazu y Basualdo (1995), y Azpiazu, Bang y Nochteff (1995).
}

zación de Cooperación y Desarrollo Económicos (OCDE), las reformas se concentraron en un conjunto de medidas que incluían la introducción de mecanismos de mercado, el cambio de las funciones de los cuerpos centrales de administración y gestión y la descentralización, mucho más que en las privatizaciones (OCDE, 1993).

La rapidez y la amplitud del proceso fueron mucho mayores que las usuales en el mundo occidental: en cuatro años se privatizaron casi todas las empresas industriales y de servicios estatales.

Los criterios y las acciones gubernamentales exhibieron cambios y faltas de continuidad muy marcados que afectaron la capacidad de negociación estatal.

En general, la creación de marcos y organismos fue casi simultánea con las privatizaciones y en algunos casos posterior a ellas.

Las privatizaciones fueron utilizadas principalmente como parte de la política macroeconómica de corto plazo, en especial para compensar el desequilibrio fiscal y el de cuenta corriente, y para crear condiciones que permitieran mantener el tipo de cambio fijo, sacrificando los objetivos de largo plazo.

Hubo una continua y recurrente renegociación de las normas bajo las cuales se privatizo, en gran parte de los casos para ganar la confianza de las grandes empresas. Esto elevó los costos sociales, debido a los beneficios que el Estado concedió después de reconocer que las empresas tenían derechos adquiridos y que los cambios podían afectar sus utilidades futuras.

La total despreocupación por difundir la propiedad -en contra de las experiencias y recomendaciones internacionales--impulsó una fuerte concentración económica, tanto dentro de las compañías privatizadas, en las que los compradores tienen asegurado el control, como en el conjunto de la economía. Un pequeño grupo de conglomerados se diversificó hacia actividades totalmente heterogéneas, y alcanzó una presencia decisiva en casi toda la gama de actividades privatizadas. Esta "diversificación heterogénea" obstaculiza la eficiencia microeconómica y la especialización tecnoproductiva. ${ }^{38}$

\footnotetext{
${ }^{38}$ Esta diversificación no see efectúa en torno a un núcleo tecnoproductivo en actividades de mediana y alta tecnologia, generalmente en el sector transable (a diferencia de lo que ocurre en las economías desarrolladas) ni en un número reducido de núcieos de ese tipo (como suele suceder en las EaR). Por ejemplo, uno de los mayores conglomerados locales se ha diversificado, ampliándose desde la siderurgia hacia la distribucion de electricidad, el transporte de gas, la distribución de gas, la explotación de petrobleo, el servicio de telecomunicaciones, el transponte ferroviario, los servicios portuarios y las concesiones viales (Basualdo, 1994).
} 
La debilidad regulatoria y las características mencionadas fueron factores decisivos para la consolidación de posiciones desde las cuales se pueden obtener cuasi rentas de privilegio. Los grandes conglomerados obtuvieron: i) un muy significativo aumento de los patrimonios que reforzó su capacidad de financiarse en el exterior a tasas muy inferiores a las internas; ii) condiciones bajo las cuales el riesgo es bajísimo o nulo; iii) amplios márgenes para la fijación de precios; iv) una gran libertad para aumentar sus costos, transfiriendo utilidades a empresas vinculadas (por ejemplo, en la compra de equipamiento o en la contratación de servicios), y v) una influencia significativa sobre los precios y las rentabilidades relativas de la economía. Un indicador de ello es la altísima participación de los servicios públicos y el complejo petrolero privatizados en las utilidades de las 20 empresas con mayor masa de ganancias.

Esta concentración del poder económico, así como la consolidación de reservas de mercado con cuasi rentas de privilegio, dificulta la emergencia de una nueva y más competitiva clase empresaria. Por otra parte, la concentración de la propiedad de las empresas privatizadas, reforzada por tenencias accionarias cruzadas y acuerdos empresariales, se suma a la debilidad de los marcos y las agencias regulatorios para incorporar rigideces y restricciones. Entre éstas cabe mencionar i) una inversión planeada inferior incluso al bajísimo nivel de los años ochenta; ii) el aumento del riesgo de cooptación de las agencias reguladoras, agravado por la creación de agencias específicas para cada servicio, con escasa o nula coordinación entre sí; iii) el reforzamiento de barreras a la entrada distintas de las tecnoproductivas; iv) la creciente asimetría en la capacidad de negociación entre el Estado y los conglomerados, ya que éstos controlan los servicios públicos, pero el Estado sigue siendo el responsable del servicio en última instancia; v) la pérdida de capacidad de negociación del resto de los agentes privados frente a los conglomerados, y vi) una creciente opacjdad de los mercados y el riesgo consecuente de prácticas de precios de transferencia. Un ejemplo de estos últimos problemas es la imposibilidad de acceso público a los contratos de provisión entre los transportadores, los distribuidores y los grandes usuarios de gas, o entre los generadores y los grandes usuarios de energía eléctrica (en muchos casos pertenecientes al mismo conglomerado).

En resumen, muchos de los rasgos que adoptó el proceso de privatización y desregulación argentino ${ }^{39}$ llevaron, en última instancia, a mayores imperfecciones del mercado, a mayores divergencias entre beneficios privados y sociales, y a iguales o mayores distorsiones internas, y a la vez reforzaron la tendencia hacia una economía semicerrada, oligopólica y centrada en las cuasi rentas de privilegio.

De hecho, este proceso contribuyó de manera decisiva al cambio de rentabilidades relativas en contra de la de los bienes transables. Además, mientras los precios de otros bienes no transables que influyen sobre los costos de los transables pueden ser reducidos mediante la devaluación o la deflación, ninguna de estas dos medidas puede reducir significativamente los precios de los servicios públicos privatizados, debido a que éstos están implícita o explícitamente indexados por el tipo de cambio, o debido a su baja elasticidad, al carácter oligopólico de los mercados respectivos o a alguna combinación de estos factores.

\section{IV}

\section{Algunas conclusiones}

"Economic hissory is overwhelmingly a story of economies
that failed to produce a set of economic rules of the
game that induce sustained economic growsh."

Douglas North

Las reformas estructurales y las políticas económicas aplicadas en Argentina desde 1991 llevaron a una burbuja liderada por las formas que adoptaron el endeudamiento, las privatizaciones, la desregulación y la

\footnotetext{
${ }^{39}$ Estos rasgos diferencian al proceso de privatización y desregulación argentino de las experiencias de privatización exitosas, y en cambio lo asemejan muchas veces a las más negativas de Europa oriental (sobre éstas, véase ocDE, 1994).
} 
liberalización comercial; esta burbuja reforzó en las elites económicas la búsqueda de cuasi rentas de privilegio, no vinculadas a la tecnología, la inversión y la competencia en los mercados externos, y condujo a una nueva regresión en la estructura económica ${ }^{40}$ y en el comercio exterior, y a una economía tan cerrada como la del período de industrialización sustitutiva de las importaciones.

Las recomendaciones de lo que Ralph Dahrendorf llamó el conservatism of unconcern (conservadurismo de la despreocupación), recogidas en buena parte en los planteamientos neoconservadores, convergen con el comportamiento socioeconómico de la elite económica tradicional argentina (y de muchos países de la región), creando nuevas restricciones a la transición hacia una economía más abierta, dinámica, innovadora y competitiva. Frente a ello, siguiendo la observación de Schumpeter (1968), es razonable pensar que la investigación y el debate académico y de políticas públicas debería atender cada vez más a los problemas que surgen en la interacción de las instituciones y el empresariado o, en general, de las instituciones, agencias y organizaciones propias de cada economía, ya que la construcción de instituciones eficientes y de un sistema de contrapesos y consensos entre actores sociales es una condición necesaria para el desarrollo (Nochteff, 1994).

\section{Bibliografia}

Argentina, Ministerio de Economía y Obras y Servicios Públicos (1995): Informe económico, año 4, $\mathrm{N}^{\circ} 15$, Buenos Aires, Secretaría de Programación Económica, diciembre.

Azpiazu, D. y E. Basualdo (1987): Cara y contracara de los grupos económicos, Buenos Aires, Cántaro.

(1995): Las privatizaciones en la Argentina. Concentración del poder economico e imperfecciones de mercado. La privatizacion en América Latina y el Caribe: algunas experiencias nacionales y sectoriales; $N^{\circ} 3$, Caracas, Sistema Económico Latinoamericano (SELA) Reunión de Altos Funcionarios encargados de los Procesos de Privatización en América Latina y el Caribe.

Azpiazu, D., E. Basualdo y M. Khavisse (1987): El nuevo poder económico en la Argentina de los años ochenta. Buenos Aires, Legasa.

Azpiazu, D. y H. Nochteff (1994a): El desarrollo ausente. Restric ciones al desarrollo, neoconservadurismo y elite económica en la Argentina. Ensayos de economía politica, Buenos Ajres, Tesis/Norma.

(1994b): Industrial Performance and Transition of Eco. nomic Systems. The Argentine Steel Industry, Buenos Aires, Facultad Latinoamericana de Ciencias Sociales (FLACSO).

Azpiazu, D. y A. Vispo (1995): Algunas enseñanzas de las privatizaciones en Argentina, Revista de la CEPAL, $\mathrm{N}^{\circ} 54$, LC/G.1845-P, Santiago de Chile. Comisión Económica para América Latina y el Caribe (CEPAL).

Azpiazu, D., J. H. Bang y H. Nochteff (1995): Privatizacion, desregulación y precios relativos en la Argentina de los noventa, Buenos Aires, FLACSO.

Basualdo. E. (1987): Deuda externa y poder económice en la Argentina. Buenos Aires, Nueva América.

(1994): El impacto económico y social de las privatizaciones, Realidad económica, $\mathrm{N}^{\circ} 123$, Buenos Aires, Instituto Argentino para el Desarrollo Económico (IADE).

Barbeito, A. y R. Lo Vuolo (1993): La nueva oscuridad de la politica social, Buenos Aires, Centro de Investigaciones en Políticas Públicas (CEPP).

${ }^{40}$ Según Nochteff (1994), esta regresión continuó ta iniciada a mediados de los años setenta.
Beckerman, M. y P. Sirlin (1996): Patrón de especialización y politica comercial en la Argentina de los noventa, Buenos Aires. mimeo.

Bessant, J. (1991): Managing Advanced Manufacturing Technology. The Challenge of the Fifth Wave, Manchester, Oxford, Reino Unido, NCC Blackwell.

Bisang, R. (1995): Las exportaciones argentinas y el Plan de Convertibilidad, Ministerio de Relaciones Exteriores y Culto, Programa de Fomento de las Exportaciones/Programa de las Naciones Unidas para el Desarrollo/CEPAL, febrero, mimeo.

Burns, T. y T. Dietz (1995): Human agency and evolutionary process, B. Wittrock (ed.), Agency in Social Theory, Londres, Sage.

CEPAL (1995): Balance Preliminar de la Economía de América Latina y el Caribe, LC/G. 1892-P, Santiago de Chile, diciembre. Publicación de las Naciones Unidas, $\mathrm{N}^{\circ}$ de venta S.E.95.Il.G.18.

Cepeda, H. (1995a): Una vision sobre el desempeño exportador de 1994: el caso de las manufacturas de origen industrial. Nota $\mathrm{N}^{\circ} 51$, Buenos Aires, Unión Industrial Argentina (UIA)/nstituto para el Desarrollo Industrial (IDI), agosto.

(1995b): Una visión sobre el desempeño exportador de 1994; el caso de las manufacturas de origen agropecuario. Nota $\mathrm{N}^{\circ} 53$. Buenos Aires, UiAlDl, diciembre.

Cereijido, M. (1990): La nuca de Houssay, Buenos Aires, Fondo de Cultura Econónica (FCE).

Coloma, G. (1993): Desempeño empresario y contexto económico, DT 12, Buenos Aires, UIA/ID].

Cortés, R. (1985): Cambios en el mercado de trabajo urbano argentino, 1974-1983. Buenos Aires, FLACSO.

Chudnovsky, D. y A. López (1994): Foreign Direct Investment in Argentina, Buenos Aires, Centro de Investigaciones para la Transformación (CENIT)/hDCl.

(1995): Política tecnológica en la Argentina: ¿Hay algo más que laissez-faire?. Buenos Aires, CENIT.

Diamand, M. (1988): La estructura productiva deseguilibrada y la doble brecha, Cuademo $\mathrm{N}^{\circ} 3$, Buenos Aires, Centro de Estudios de la Realidad Económica (CERE).

Díaz, A. (1995): La industria chilena entre 1970 y 1994: de la sustitución de importaciones a la segunda fase exportadora, LC/R.1535, Santiago de Chile, CEPAL/Centro Internacional de Investigaciones para el Desarrollo (CIID). 
Dosi G., C. Freeman, R. Nelson, G. Silverberg y L. Soete (eds.) (1988): Technical Change and Economic Theory. Londres, Pinter Publishers, Lid.

Esser, K. (1991): Development of a Competifive Strategy: A Challenge to the Countries of Latin America in the 1990's, Berlín, Instituto Alemán para el Desarrollo.

Esser, K., W. Hillebrand, D. Messner y J. Meyer-Stamer (1993): International Competitiveness in Latin America and East Asia. Londres, Frank Cass.

Fanelli, J. M., O. Kacef y J. L. Machinea (1995): Precios relativos y competitividad industrial, Buenos Aires, UIA/IDl, mimeo.

FIDE (Fondo de Inversiones para el Desarrollo Económico) (1996): Anuario Estadístico, Buenos Aires.

FIEL, (Fundación de Investigaciones Económicas Latinoamericanas) (1996): Indicadores de coyuntura, Buenos Aires, enero.

FMI (Fondo Monetario Internacional) (1986): Argentina: incentivos fiscales para el desarrollo, Washington, D.C..

Freeman, C. (1982): The Economics of Industrial Innovation, Londres, Francis Pinter.

Gaggero, J. (1995): Empresas privatizadas y crisis de la regulación, Perspectiva, affo 7, $\mathrm{N}^{\circ} 8$, Buenos Ajres.

Heymann, D. (1984): Precios relativos, riqueza y producción, Ensayos económicos, $\mathrm{N}^{\circ} 29$, Buenos Aires, Banco Central de la República Argentina, marzo.

Hikino, T. y A.H. Amsden (1995): La industrialización tardía en perspectiva histórica, Desarrollo económico, vol. $35, \mathrm{~N}^{\circ} 137$, Buenos Aires, Instituto de Desarrollo Económico y Social (IDES), abril-junio.

Kacef, O. (1994): Algunas consideraciones sobre la composición de la inversión, Nota $\mathrm{N}^{\circ} 43$, Buenos Aires, ULA/LDI.

Kalecki, M. (1965): Theory of Economic Dynamics. An Essay on Cyclical and Long-run Changes in a Capitalist Economy, Nueva York, George Allen \& Unwin.

Kaplinsky, R. (1993): Export processing zones in the Dominican Republic: Transforming manufactures into commodities, World Development, vol. 21, $\mathrm{N}^{\circ} \mathrm{I1}$, Oxford, Reino Unido. Pergamon Press Ltd.

(1995): The new competition and human resources: How disadvantaged are low income LDCs?, trabajo preparado para la Conference on Globalization and Learning, Oxford, Reino Unido, University of Sussex, Institute for Development Studies (IDS), 23 de septiembre.

Krugman, P. (1995): Dutch tulips and emerging markets, Foreign Affairs, vol, 74, $\mathrm{N}^{\circ} 4$, Nueva York, Council on Foreign Relations, Inc., julio-agosto.

Llach. J.J. (1987): Reçonstrucción o estancamiento, hesis de grado, Buenos Aires, Asociación de Bancos Atgentinos (ADEBA), mimeo.

Machinea, J. L. (1996): ¿Es tan alta nuestra deuda?, Clarín, Buenos Aires, 5 de marzo.

Mallon, R. y J. V. Sourrouille (1976): La política económica en una sociedad conflictiva. El caso argentino, Buenos Aires, Amorrortu.

Marcó del Pont, M. (1995): Responsabilidades de la política economica en el aumento del desempleo, Minutas, Buenos Aires, Movimiento Industrial Nacional (MIN), julio-diciembre.

Messner, D. y J. Meyer-Stamer (1994): Sistemic competitiveness. Lessons from Latin America and beyond. Perspectives for Eastern Europe, The European Journal of Development Research, vol 6, $\mathrm{N}^{\circ} 1$, Londres, Frank Cass.
Minujin, A. (ed.) (1993): Desigualdad y exclusion. Desafios para la polática social en la Argentina de fin de siglo. Buenos Aires. Fondo de las Naciones Unidas para la Infancia (UNICEF)/Edjtorial Losada.

Napoleoni, C. (1962): Rentas de escasez, en Napoleoni, C. (ed.), Diccionario de economía política, Madrid, Castilla.

Nochteff, H. (1993): Constraints on the Transition to a Dynamic Economic System in Latin America. An Approach to some Socio-Economic Conditionants for Development: the Argentine Case, Buenos Aires, FlaCSO.

(1994): Los senderos perdidos del desarrollo. Elite económica y restricciones al desarrollo en la Argentina, D. Azpiazu y $\mathbf{H}$. Nochteff, El desarrollo ausente. Restriccione. al desarrollo, neoconservadurismo y elite economica en ta Argentina. Ensayos de economía política, Buenos Aires, Tesis/ Norma.

(1995): The transition of the Argentine economic system. A report of research findings, Addendum, Berlín, mimeo.

North, D. (1990): Institutions, Institutional Change and Economic Performance, Cambridge University Press.

Nun, J. (1995): Argentina: Science, technology and public policjes, M.I. Bastos y Ch. Cooper (eds.), Politics of Technology in Latin America, Londres y Nueva York, Routledge.

OCDE (1993): (Organización de Cooperación y Desartollo Económicos): Public Management Developments. París. (1994): Trends and Policies in Privatization, vol II, $\mathrm{N}^{\circ} 1$, París.

Platteau, J,P. (1994): Behind the market stage where real societies exist. Part I: The role of public and private institutions, The Journal of Development Studies, vol. 30, $\mathrm{N}^{\circ} 3$, Londres, Frank Cass \& Co. Ltd., abril.

Poli, F. y M. Peirano (1996): A propósito del endeudamiento externo, Informe industrial, año XVIII, $\mathrm{N}^{\circ} 149$, Buenos Aires, marzo.

Porta, F. (1995): Argentina: cuatro afios con tipo de cambio fijo. ¿Ajuste estructural o ajuste recesivo?, Revista de ciencias sociales, $\mathrm{N}^{\circ} 3$, Buenos Aires, Universidad Nacional de Quilmes, noviembre.

Ricardo, D. (1826): Principles of Political Economy and Taxation, Londres, Penguin Books.

Sábato, J. F. (1988): La clase dominante en la Argentina moderna. Formación y caracteristicas, Buenos Aires, Centro de Investigaciones Sociales sobre el Estado y la Administración (CISEA)/Grupo Editor Latinoamericano (GEL).

Schumpeter, J.A. (1957): Teoría del desenvolvimiento económico. México D.F., FCE.

(1968): La respuesta creadora en la historia económica, Ensayos, Barcelona, Oikos-Tau (artículo aparecido en el Journal of Economic History en noviembre de 1947).

Schydlowsky, D. (1993): Foreign Exchange Regimes for Dutch Disease Prone LDCs, Washington, D.C., The American University, mimeo.

Sorrouille, J. V. y J. Lucángeli (1980): Apuntes sobre la historia reciente de la industria argentina, Boletín informativo Techins, $\mathrm{N}^{\circ} 129$, Buenos Aires.

UNCTAD (Conferencia de las Naciones Unidas sobre Comercio y Desarrolto) (1995): Informe sobre comercio y desarrollo 1995 . Nueva York. 